\title{
FDA drug approvals: No worse is simply not good enough
}

The US Food and Drug Administration (FDA, Rockville, MD) was recently put on notice by the US Congress. At the end of last year, Republican Senator Nancy Kassebaum of Kansas introduced the FDA Performance and Accountability Act as a kid-gloved way of bringing the FDA in line with the so-called "Contract with America." The new thinking in Washington these days is that government agencies should be facilitators of business rather than stunters of its growth. According to this thinking, the FDA, as public servant, should be held accountable for the extra burden it puts on the public when it causes unjustifiable delays in drug development, in much the same way that drug developers are forced to justify their therapeutics' safety and efficacy to the FDA.

Special interest groups, such as the Biotechnology Industry Organization (BIO, Washington, DC) and the Pharmaceutical Research and Manufacturers of America (PhRMA, Washington, DC), as well as patient activist groups, have applauded the Kassebaum effort as long overdue. "The United States leads the world in drug discovery," says Gerald J. Mossinghoff, PhRMA's president, "now it's time for it to lead the world in drug approvals." "There are people waiting for new medicines being developed by biotechnology companies," says Carl B. Feldbaum, BIO's president, "The single goal of the reform effort should be to get those medicines to the people who need them as soon as possible."

FDA Commissioner David Kessler recently responded to these criticisms - and to the call for reform - at the Massachusetts Biotechnology Council annual meeting (Boston, MA): "It is time to put to rest the incorrect perception that American patients generally suffer because of a socalled drug lag," he said, "While there will always be an occasional exception, we approve most important new drugs first."

Is there a drug approval lag or not? "In many ways, the US is comparable to the UK," says Stuart R. Walker, director of the Centre for Medicines Research (CMR, Carshalton, UK), and one of the authors of the preliminary report (part of which will be published this month in CMR's newsletter) from which Kessler took some of the data to justify his remarks. While the report stresses that there are limitations as to the kinds of conclusions that can be drawn from comparisons between mean or median approval times, as a rule of thumb, Walker says, "Between 1990 and 1995, review times in the US were no worse than anywhere else." The report states that, for drugs submitted within six months of each other in the US and UK, the US reviewed six of nineteen compounds in virtually the same time as the UK, while lagging behind in nine reviews. Of the nine reviews in which the US came in second, the greatest difference between US and UK approval times was greater than a year in only two cases. The report goes on to show that the FDA has made steady improvement in lowering its mean approval times since the late 1980s-most dramatically in 1994 (the latest year for which final figures are available).

Does this mean that the Congress, drug developers, and patient advocacy groups should drop their efforts to reform the FDA? Absolutely not. While we applaud the FDA's apparently successful efforts to streamline the agency, and hope that the agency will continue to improve, the fact that it is "no worse than anywhere else," is not sufficient grounds to recommend that it continue to be run without independent oversight. The agency needs to be accountable for its actions, and despite Kessler's efforts to show that it will improve on its own, there is little doubt that these improvements would not have occurred without the sustained lobbying of drug makers and patient advocacy groups alike.

The real question for biotechnology drug makers is whether the measures proposed by Kassebaum will be sufficient to propel the FDA into the 21 st century. As pointed out in Stanley T. Crooke's article "Comprehensive Reform of the Drug Regulatory Process" (Bio/Technology 13:25, January 1995), methods of drug discovery and development have undergone a revolution-which the FDA has failed to match. While simple FDA reform may aid traditional pharmaceutical development, will it really help reduce the regulatory burden on the innovative therapeutics that will continue to emerge from biotechnology? What the CMR report and Commissioner Kessler fail to point out in their analysis is the fact that for emerging biotechnology companies, being forced to wait 9 out of 19 times for periods of more than a year for US approval versus UK approval is not trivial. For biotechnology companies, and for patients waiting for these therapies, such delays can be devastating.

One alternative to the Kassebaum legislation, a recent proposal by the Progress and Freedom Foundation (PFF, Washington, DC), suggests it is time for the FDA to undergo a dramatic reformatting--rather than simple reform - to catch up with the technologies it is regulating. The authors of "Advancing Medical Innovation" suggest that it is only, "through a fundamental change in the framework used to bring new medical products to market. ..." that total development times and product availability times will be improved. The authors propose to have oversight of clinical product development and reviews of the results performed by the private sector. The FDA's function would be to license and oversee private sector "drug certification bodies" (DCBs), which would consist of the "experts qualified by scientific training and experience" that the law currently requires to ensure the regulatory compliance of all parties in the system, and to have final review and signoff of any recommendation the DCBs make for approval. The FDA would also manage the national drug safety system, as it does now. The proposal concludes that removing the inefficiencies of a monopolistic federal agency from these steps and establishing private sector competitors would enable better service to be offered to sponsors while maintaining standards of safety more similar to those now employed in Furope.

So far, the PFF proposal has received little attention because it has been overshadowed by the proposed Kassebaum legislation. But the idea of reformatting the FDA — not just reforming it - should be given serious consideration by all legislators and drug makers and patients who are not satisfied with an FDA that is "no worse than anywhere else."

\section{Xenotransplantation and the "yuk" factor}

When the Nuffield Council on Bioethics (London) issued its recent report- "Animal-to-Human Transplants: The Ethics of Xenotransplantation"-it was probably inevitable, regardless of the content of the report, that the general media would seek out the flaws in 